\title{
Article \\ Subject (in) Trouble: Humans, Robots, and Legal Imagination
}

\section{Ana Oliveira}

Centre for Social Studies, University of Coimbra, 3000-995 Coimbra, Portugal; anaoliveira@ces.uc.pt

Academic Editor: Margaret Thornton

Received: 30 September 2019; Accepted: 30 March 2020; Published: 31 March 2020

Abstract: The legal conception and interpretation of the subject of law have long been challenged by different theoretical backgrounds: from the feminist critiques of the patriarchal nature of law and its subjects to the Marxist critiques of its capitalist ideological nature and the anti-racist critiques of its colonial nature. These perspectives are, in turn, challenged by anarchist, queer, and crip conceptions that, while compelling a critical return to the subject, the structure and the law also serve as an inspiration for arguments that deplete the structures and render them hostages of the sovereignty of the subject' self-fiction. Identity Wars (a possible epithet for this political and epistemological battle to establish meaning through which power is exercised) have, for their part, been challenged by a renewed axiological consensus, here introduced by posthuman critical theory: species hierarchy and anthropocentric exceptionalism. As concepts and matter, questioning human exceptionalism has created new legal issues: from ecosexual weddings with the sea, the sun, or a horse; to human rights of animals; to granting legal personhood to nature; to human rights of machines, inter alia the right to (or not to) consent. Part of a wider movement on legal theory, which extends the notion of legal subjectivity to non-human agents, the subject is increasingly in trouble. From Science Fiction to hyperrealist materialism, this paper intends to signal some of the normative problems introduced, firstly, by the sovereignty of the subject's self-fiction; and, secondly, by the anthropomorphization of high-tech robotics.

Keywords: subject self-fiction; sex-robots; posthuman

\section{Introduction}

This paper ${ }^{1}$ presents some ideas that contribute to the discussion about the meaning and the place of the subject in legal reasoning and imagination. This aim draws inspiration from the subject trouble, an obvious reference to Judith Butler' Gender Trouble (Butler 1990), by illustrating, articulating, and thickening the troubles with the subject, (subjected to be) inescapably constituted and mediated as a legal subject.

The making of a legal person (someone who can act in law)—with all the makings of legal non-persons (those who cannot act in law and who are generally thought of as property) — which is perhaps, as Naffine (2003, p. 247) observed, the greatest political act of law has prompted canonical questions, such as who and what counts as a legal person. In this paper, I will address two ontological-oriented ramifications: in the first part, I will discuss which aspects of the subjects' subjectivity are at their disposal; and, in the second part, who and what counts as human. It will go

1 This essay results from a paper presented at the Congress Linking generations for global justice, organized by the Oñati International Institute for the Sociology of Law and the Research Committee on Sociology of Law, 19-21 June 2019. I want to thank Margaret Thornton for her generous encouragement, reading, and comments on this work. I also thank Tiago Ribeiro, Tiago Faleiro, and Adriana Bebiano for their careful readings and remarks. 
through some examples that help questioning the field, to probe its conditions of possibility, holding on some cases (such as the one of Ratelband, Raphael Samuel, Sophia, or Samantha) and domains [such as time (age), life (birth), humanity (sentience), relationality (care)] that bring in itself the critical and analytical potentiality of the legal subject as an expression of (or struggle for) existence.

This is an essay that maps some legal issues and normative problems which are introduced, firstly, by the (claiming of) sovereignty of a subject's self-fiction and, secondly, by the anthropomorphization, ${ }^{2}$ as a condition of humanity, of robots. Far from being an exhaustive or dense theoretical text, it is an interpellation exercise instigated by cases whose political-legal enunciation challenges the legal framework, the legal conception and interpretation of the subject, and the role of law in the government of social interactions. Therefore, it is in its essayistic quality that the following normative and epistemological problems shall be read.

\section{Subjects ${ }^{\circledR}$ and Subjectivities ${ }^{\mathrm{TM}}$}

The legal conception and interpretation of the subject of law are an old matter/problem in the theory and philosophy of law ${ }^{3}$ and have long been challenged by different theoretical backgrounds: from feminist critiques of the patriarchal nature of law and its subjects; ${ }^{4}$ to the Marxist critiques of law as an ideological state apparatus (its superstructural position in the capitalist productive system-cf. Althusser (1970)); to the anti-racist critiques of its colonial nature. ${ }^{5}$ Feminist, Marxist, and colonial perspectives have denounced narrative legal devices that produce and validate the referent of law: a subject who simultaneously is male, white, socially productive, and mindful of his property.

These perspectives have been challenged by anarchist, queer, and crip approaches that denounce its modern character (rationality, macronarratives, etc.), the binary way of organizing the world and the ableness-blindness that characterizes all of the above and that represents the primary axis of human, inhuman, and ahuman - as an absence of humanity that characterizes human beings. For example, in cases of abortion, the malformation of a fetus or what is called infeasible fetus is a condition that suspends the penal and the social censorship towards an interruption of pregnancy. In this regard, from a crip theory approach (and Christian, actually) being — to be-is already an allowance, an axiological outcome. Actually, this state-run regulation notion on who may, or who may not, be born is pretty much Michel Foucault's concept and thesis of biopolitics. The merit of crip theory popularity rests on providing the activist grammar for denouncing, at an individual level, which was presented from a structural point of view. Still within the notion of who may, or may not, be born, a queer theory approach, such as the one presented by Preciado (e.g., Preciado 2008), has denounced the fiction and biopolitical obsession with the two sexes' regime, either through the compulsory corrective surgeries - and corrective must be underlined here—of intersex babies and through the legal imposition of being one sex; of being constituted as a sex of one's own (a wordplay from Virginia Woolf A Room of One's Own). Even the legal availability of a third sex, which has been announced in some countries, such as Germany, ${ }^{6}$ does not question the nature of the truth of this regime or the truth of

2 Anthropomorphism, from the Greek ánthrōpos (meaning human) and morphē (meaning form), is the attribution of human traits, emotions, or intentions to non-human entities.

3 What is it to be a legal person? Who and what counts as a person in law (who can act in law and who cannot-generally thought of as property) are some of the questions revised by Ngaire Naffine (Naffine 2003), which systematizes three classic approaches/groundings to 'the person': (i) technical, the person is a pure legal abstraction and artifice (a formal, abstract, but nonetheless highly convenient device of law); (ii) metaphysical, the person is defined by the uniquely human nature, the possession of a soul, or by the capacity for reason, and therefore by the moral and legal responsibility; (iii) liberal, the person is a rational and moral agent, an intelligent, responsible, and competent subject, the paradigmatic rights holder.

4 E.g., (Smart 1989; Fineman and Thomadsen 1991).

5 E.g., (Merry 1994; Harris 1990).

6 According to Baars (2019, p. 58), "[t]he main criticisms are that the third option, which was adopted into law in 2018, does not fully recognise gender diversity as it will only be available to those with a medical diagnosis of an intersex condition, and also that the government failed to genuinely consider the alternative option presented by the Constitutional Court- that of scrapping sex/gender registration altogether". 
its nature; which ultimately is called Nature (with an uppercase " $\mathrm{N}$ "). This third option, this new possibility of categorizing existence at the same time that it validates the elasticity of self-fictions reinforces its structure and meaning; and, by providing and allowing escape-categories for subjects, forsakes the denouncing of such structures, of its regime.

In this sense, anarchist, queer, or crip conceptions-as examples of established theoretical frameworks which I will not deepen here-have posed several dilemmas to the academic field of humanities, social sciences, and legal studies, by bringing about a critical return to the subject, the structure and the law, as unfinished and constituent objects of social life. These standpoints serve simultaneously as inspiration for arguments that deplete the structures and render them hostage of the sovereignty of the subject self-fiction: from invoking the figure of civil disobedience in shoplifting cases; to the right not to perform surgery on someone to prevent them from being blind or deaf; to invoking the right to change civil age as an equivalent to the right of changing name and sex, as argued in the case of Emile Ratelband.

Emile Ratelband is a Dutch citizen who filed a legal proceeding to change his civil age. In December 2018, Arnhem Court rejected his request. ${ }^{7}$ Media coverage of this case focuses on the burlesque of the situation; however, it introduces pertinent questions to the field of social and cultural studies of law by exposing and challenging the terms and the boundaries of allowance, or legal recognition, of a subject self-fiction. Emile Ratelband is, or was by that time, 69 years old. He filed a lawsuit in order to see recognized, in his identity card, the age he appeared to have, or he felt to have, attested also by his doctor who avowed that his body and health were those of a 45-year-old person. Quoted in many interviews, Ratelband affirmed that he felt rejected; in his own words: "I feel that I am between 40 and 45 years old, but my ID says that I am 69. I suffer discrimination; I cannot relate to women in the same way as if I was 45 , nor ask for a mortgage or find the job I want".

Ratelband's argument was double: on the one side, he affirmed he was being discriminated on the basis of his age (what has become known as ageism); on the other, he wondered why he was not able to change his age, while there was a possibility to change someone's sex or name. The Dutch Court held that Dutch law does not offer the possibility of changing the date of birth of a citizen nor the actual age for two main reasons. First, changing the date of birth would make null and void 20 years of records (namely birth, death, and marriage records), which would have a variety of undesirable legal and social implications. Second, because age is linked to different rights (such as voting, signing contracts, drinking, or driving) and to different protections (for example, in the criminal sphere, the crimes against sexual self-determination of underage individuals). However, as stated by the same court, Ratelband might "use other legal tools to fight against discrimination" based on age.

From the normative problems that this and other cases raise to social and cultural studies of law-namely from the operative concept and sociolegal meaning of discrimination-The Curious Case of Emile Ratelband (that might inaugurate a new expression of dysphoria, that of age) points out the increasing bio-political and socio-legal densification of the subject. If «I» am what «I» feel «I» am (further validated by medical expertise); if «I» have the right to be who «I» want to be (further encouraged by most ad campaigns), why is this permission restricted to identity-sexuality? Why shouldn't subjects be able to self-determine themselves in terms of age ${ }^{8}$ or race, ${ }^{9}$ etc.? Is discourse-mediated identity, as a technology of the self, primarily or predominantly sexual? Or, as

7 "Dutch man, 69, starts legal fight to identify as 20 years younger", The Guardian, 8 November 2018, available at: https: //www.theguardian.com/world/2018/nov/08/dutch-man-69-starts-legal-fight-to-identify-as-20-years-younger. "Dutch court rejects man's request to be 20 years younger", The Guardian, 3 December 2018, available at: https://www.theguardian.com/ world/2018/dec/03/dutch-court-rejects-emile-ratelband-request-20-years-younger.

8 In terms of age, and please take lightly the confessional tone, this would allow me to be recognized as a 70-year old person and apply for retirement (which I might be eager for); or it would allow people to be recognized as a 14-year old person and to have sexual encounters with people of the same age (what some people may also be eager for).

9 In this regard, the case of civil rights activist Rachel Dolezal—nicknamed by media as a "race faker" - is particularly paradigmatic. Establishing an equivalent between the narrative of fluid, non-binary gender identity and racial identity, Rachel Dolezal argues: "It's very similar, in so far as: this is a category I'm born into, but this is really how I feel. 
theorized by Hall (1996), once identity, which is but an interpretative concept, only makes sense to those who need it, is sexual identity the identity that subjects have needed the most (while attempting to attribute meaning to themselves)? A meaning that only exists through the mirror of social and political context that reflects it and that is part of the process by which "human beings are made subjects" (Foucault 1982, p. 777). The terms of such interpretative mirror (device of subjectivation and government)—or the "effects of power", privileged object of the Foucauldian legacy that seeks to understand power relations in the fabrication of truth and knowledge-are in constant negotiation: some terms are accommodated and validated (namely by the medical and forensic diagnosis of dysphoria, or by the creation or the claim of the legal category 'third sex'); some are dismissed (as the availability to self-determine one's age).

One other case became widely mediatized in February 2019: Raphael Samuel, a 27-year-old Indian, intended to sue his parents on the ground that they did not ask for his consent or asked him if he wanted to be born. Inspired, or maybe not, by the movie Capernaum, Palme d'Or in Cannes Festival in 2018, directed by the Lebanese Nadine Labaki-in which a 12-year-old boy also sued his parents, negligent parents, for the fact that he had been born without his consent and for making him live a miserable life. Both in the movie, and in Raphael Samuel's intentions, there is a moralizing outcome on birth control: Zain, the protagonist of Capernaum, wanted to prevent his parents from having more children; Raphael Samuel wants humanity to stop reproducing itself. Raphael's mother made public that, if Raphael can come up with a rational explanation on how she could have obtained his consent to be born, then she would accept her guilt. ${ }^{10}$

What this case introduces is a further groundbreaking level of disposing of the self, as a birthright not to be born-when we are familiar with the opposite argument, namely in anti-abortion campaigns: the right to be born. In this sense, it both problematizes the so far unquestioned legally original premise of existence- the radical impossibility of consenting to it-as it challenges the possibility of existence through its active non-existence. The question is not about assisted death, or euthanasia, or the right to die; it is not presumably a celebration of suicide (as in the 2019 folk horror film Midsommar); it is a matter of claiming the right not to be born. In addition, as claims-the right not to be born, the right to be born, the right to die, the right not to die-they compellingly confront the subject, structure and law, but they also exemplify the academic driven epistemological turn towards the sovereignty of the subject-identity being one of its variations has the merit of, by functioning as an individual resource, turning the subject (state) governable. In this LEGO Subjects ${ }^{\circledR}$ and Subjectivities ${ }^{\mathrm{TM}}$, the epistemological turn has not been towards how experiences are shaped by overlapping and intersecting structures and regimes that configure and operationalize subjectivities, but instead towards how subject's' self-adjectivate, that is, how subjects create the meaning of such experiences from the same adjectives with which they adjectivate (and create meaning for) themselves. My point here is not to deepen how the mainstreaming of the concept of intersectionality turned out as a political alibi, an intellectual-and legal-shortcut or a marketing-concept for funding, but to point out how the sovereignty of identity, proclaimed as a source of emancipation, validates and is validated by the production of truth provided by this disciplinarity of the subject. The popularity of the place of enunciation as a self-fiction and a shift-trigger into rights discourse- $\mathrm{I}$ am, therefore I can claim—derives, partly at least, from the great advantage it presents for national and supra-national entities that fund research: it is cheap. It is not only cheap to enhance the power-of-to-be as a power-of-being-able-to-speak-of-yourself, as it converges with selfies-selves-ego-indexed identity, as formulated by Braidotti (2019, p. 16)—as well as functioning as a prolific resource to discipline (in both senses of control and of knowledge production) the subject (also in both senses of being and of topic). Therefore, the bio-political and socio-legal densification of

“Rachel Dolezal: 'I'm not going to stoop and apologise and grovel', The Guardian, 25 February 2017, available at: https://www.theguardian.com/us-news/2017/feb/25/rachel-dolezal-not-going-stoop-apologise-grovel.

10 "Indian man to sue parents for giving birth to him", BBC, 7 February 2019, available at: https://www.bbc.com/news/worldasia-india-47154287. 
the subject, increasingly validated by identity politics, instead of witnessing the radical complication of being unspeakable (cf. Lacey 1998) and unknowable, unfolds in devices of enunciation that highlight the political-epistemological defects and paradoxes that permeate the way in which the subject's political fiction is thought, prescribed and protected.

This densification or, as I have been calling it, this political fiction or rather political imaginary may be a symptom, an effect, or an echo of something that may be termed as Identity Wars. Although lazy and not very creative, the term Identity Wars, heir of the Sex Wars, and the Theory Wars, may summarize this battle to establish meaning through which power is to be exercised. A political and epistemological battle that, in turn, is being challenged by a renewed axiological consensus, here introduced by posthuman critical theory: ${ }^{11}$ species hierarchy and anthropocentric exceptionalism. The denunciation of species hierarchy and anthropocentric exceptionalism precedes the invention of the concept of posthuman, which nowadays is already an extended field of studies, and has been materialized in vegan, which is much more than a diet, and anti-speciesism approaches, ecosexuality and sexecology activisms, and in new figurations, such as humanoids, hybrid entities, or cyborg subjectivity, as introduced in Donna Haraway's early work (Haraway 1991). Challenging human exceptionalism has created new legal issues: from ecosexual weddings with the sea, the sun, or a horse; to human rights of animals; to granting legal personhood to «nature»—as in the case of Whanganui river in Neo Zealand ${ }^{12}$ or Ganges and Yamuna rivers and their related ecosystems in India; ${ }^{13}$ to human rights of machines. Part of a wider movement on legal theory, which extends the notion of legal subjectivity to non-human agents, the subject is increasingly in trouble.

\section{To Be or Not to Be a Robot: Is It a Question?}

Rosi Braidotti (Braidotti 2019) introduces her recently published monograph Posthuman Knowledge with an image that is quite familiar to internet users: a square box to check with a cross, confirming that "I'm not a robot". According to Braidotti (2019, p. 1),

[h]aving to demonstrate one's humanity assumes as the central point of reference in the algorithmic culture of computational networks-not the human. This mundane example demonstrates that in contemporary society the human has become a question mark. Who or what counts as human today?

Who or what counts as human today? And why does it matter? Or, in other words, why did it become a question? Anthropocene, as the new great ideological consensus, the new political economy of meaning, may be a clue, through the renewed attention on nonhuman agents with the consequent reimagining of the human. The avalanche of literature on this topic has been a serious case of success in inventing new concepts, new hyphenations and neologisms: econtology; ecomaterialism; ecopathy; ecosophy; blue humanities; green humanities; capitolocene and chthulucene; anthrop-obscene; commutation ontology; placenta politics; technoanimalism; urbanibalism; robophilosophy, and so forth.

Updating the proposition humans versus machines, which is not a new phenomenon especially concerning labour spheres-early 20th century labour strikes against the introduction of machines in factories are well-known examples of this-is inspiring, premising, and justifying plenty of new

11 According to Rosi Braidotti (Braidotti 2018, p. 339): "Posthuman critical theory unfolds at the intersection between post-humanism on the one hand and post-anthropocentrism on the other. The former proposes the philosophical critique of the Western Humanist ideal of 'Man' as the allegedly universal measure of all things, whereas the latter rests on the rejection of species hierarchy and human exceptionalism".

12 "New Zealand river granted same legal rights as human being", The Guardian, 16 March 2017, available at: https: //www.theguardian.com/world/2017/mar/16/new-zealand-river-granted-same-legal-rights-as-human-being.

13 "Ganges and Yamuna rivers granted same legal rights as human beings", The Guardian, 21 March 2017, available at: https: //www.theguardian.com/world/2017/mar/21/ganges-and-yamuna-rivers-granted-same-legal-rights-as-human-beings. 
(funding for) research. ${ }^{14}$ My point is different, though. By inquiring into the moral standing that is being imprinted on social robots, I aim to problematize over how and which robots may be made subjects. Firstly, by assaying what defines, and how we can describe, the process through which robots are to be made subjects; secondly, by tackling human exceptionality: which are to be considered as the humans' exceptional social capacities, how they operate and how they can be mimicked. Sophia is a good starting point. ${ }^{15}$

Sophia-a social humanoid robot developed by Hong Kong based company Hanson Robotics, activated on 14 February 2016 - became world famous for its (hers? his? theirs?) ability to display more than 50 facial expressions. ${ }^{16}$ Invited to participate in many high-profile interviews, in October 2017, Sophia participated in a Future Investment Institute panel in Saudi Arabia, where it was asked if robots can be self-aware, conscious, and know they are robots; a question that Sophia would counter-question with the following: "well, how do you know you are human?" As an internet user, I do check the box confirming that I'm not a robot, but, beyond a false neutral, what is it to be (a) human?

In this same panel, it was made public that Sophia became the first robot to receive citizenship of a country. Sophia was granted Saudi Arabian citizenship, becoming the first robot ever to have a nationality. From parody to normative controversies, such granting introduced challenges and dilemmas with different echoes: from civil rights issues, wondering about Sophia's ability to vote or marry; to penal responsibility, as whether a deliberate system shutdown could be considered murder; to human-women rights, as under the Saudi guardianship system every woman must have a male companion with her in public, usually a close family member, who has authority to act on her behalf. ${ }^{17}$ As formulated by Braidotti (Braidotti 2019, p. 23), the mutation of capitalism into a cognitive differential machine is in full swing, so unsurprisingly we come to find Sophia doing advertising ${ }^{18}$ and advocating women' rights. ${ }^{1920}$

Anyway, the sex assigned to Saudi Arabian Sophia was not made public, but it created a new endless story: the sex of robots. Designed in Audrey Hepburn's image, Sophia has high cheekbones and a slender nose, but, as written by Maria Teresa Horta (1983 apud Ramalho 2001, p. 529), if "angels discover the vulva at the same time they know about the penis: with the legs slightly spread and shunting the wings", ${ }^{21}$ what may be in-between the legs of robots? ${ }^{22}$ Plus: why should it be important for us to know?

The sex of robots is composed in its metaphorical potential, producing meanings through comparisons, and in its metonymic projection of identity, social prosthesis, allowing, in the significance

14 A new field of studies, mostly concerned with the risk of job losses, has emerged. Take the example of the study from the Institute for Public Policy Research (IPPR), which has been receiving wide media attention, and that states that women are in a particularly vulnerable situation, as they perform tasks easily replaced by automated mechanisms (cf. Roberts et al. 2019).

15 More recently, in August 2019, Fedor (acronym for «Final Experimental Demonstration Object Research»), a Russian humanoid robot, was sent to the International Spatial Station (ISS) to learn how to help astronauts. Fedor has its own account on Instagram and Twitter, where it (he? she? they?) details his (hers? theirs?) daily life. "Earth to FEDOR: Russia launches humanoid robot into space", The Guardian, 22 August 2019, available at: https:/www.theguardian.pe.ca/news/ world/earth-to-fedor-russia-launches-humanoid-robot-into-space-343918/.

16 A video of Sophia at a Future Investment Institute panel in Saudi Arabia can be watched here: https://www.cnbc.com/video/ 2017/10/25/watch-cnbcs-andrew-ross-sorkin-interview-a-lifelike-robot-named-sophia.html.

17 "Does Saudi robot citizen have more rights than women?", BBC, 26 October 2017, available at: https://www.bbc.com/news/ blogs-trending-41761856.

18 In Portugal, Sophia appears next to Cristiano Ronaldo (a famous Portuguese football player) publicizing a television operator. The video can be watched here: https://www.youtube.com/watch?v=3ihg-iMK_60.

19 "World's first robot 'citizen' Sophia is calling for women's rights in Saudi Arabia", CNBC, 5 December 2017, available at: https://www.cnbc.com/2017/12/05/hanson-robotics-ceo-sophia-the-robot-an-advocate-for-womens-rights.html.

20 In November 2017, Sophia was named the United Nations Development Programme's first ever Innovation Champion, becoming the first non-human to be given any United Nations title. On 27 November 2018, Sophia was given a visa by Azerbaijan while attending Global Influencer Day Congress held in Baku; and on 15 December 2018, Sophia was appointed a Belt and Road Innovative Technology Ambassador by China.

21 Free translation from Portuguese.

22 In the field of social robotics, Trovato et al. (2018) have been studying the anthropometrics of robot bodies and the influence of body proportions on perceived gender of robots across cultures. 
attributed to it and by the manners it is performed (the Butlerian performativity), to reveal and inscribe an understanding and imagination of the world. An understanding and an imagination that emerges in the literature about robots and human interaction (from science fiction ${ }^{23}$ to speculative science), which in turn is profoundly shaped by a structurally binary conceptualization (being 'good and evil', 'nature and culture', 'reason and emotion', 'male and female' some of the classic examples). It is thus in the apparent inescapability of this binary structure that sexual ambiguity can only result in total disidentity (Ramalho 2001, p. 530). Moreover, the expectation boosted by the evolutionary technological process that toys, computer programs, or robots will exhibit signs of life, "even an artificial form of life, is a significant step toward the acceptance of such forms as real" (Levy 2007, p. 9). An expectation deeply sponsored and inspired by science fiction, ${ }^{24}$ which has provided new models for experimental politics, pedagogies, communities, and relations.

The movie Her, a 2013 American science-fiction romantic drama film written, directed, and produced by Spike Jonze, is an example of how, by ascribing feelings to robots, the notion of relationships is challenged. Her depicts the growing intimacy in the interaction between human and technological infrastructures, forcing the questions: can human beings have an authentic relationship with an inhuman entity? And can artificially intelligent entities become human or some hybrid form thereof?

In the movie, Theodore Twombly (played by Joaquin Phoenix), a lonely and introverted character, purchases an operating system (OS) that includes a virtual assistant with artificial intelligence, designed to adapt and evolve. Theodore and Samantha, a name chosen by the OS itself voiced by Scarlett Johansson, ${ }^{25}$ bond over their discussions about love and life, evolving into an eventual love for each other. The romantic component of the movie is encapsulated within the theme of identity: Theodore represents a futuristic Everyman, enshrouded and infused by technology; Samantha a possible Speculative-Feminist rewriting of Victor Frankenstein's creature (Mary Shelley' novel) that ends up annihilating itself.

From the dematerialization of human bodies to the counter-materialization of digital bodies, Her portrays the conceptual implications of human interactions with technology/social robotics, namely through attributing moral standing and feelings to robot-technology, and finds philosophical resonance about the ability to affect and to be affected in Baruch Spinoza (Spinoza 1994), one of the most popular and inspiring authors of posthuman epistemology. It also illustrates Johanna Seibt's (Seibt 2018) argument that currently robotic capacities are being described metaphorically, using the intentionalist vocabulary of human actions and social interactions, such as love, jealousy, desire, aspiration of fidelity, or even think or form new concepts, as if Samantha was a person.

Here and elsewhere, the preposition $a s-i f$ is presented as the:

'as-if' of fictionality and pretend-play, which has motivated ethical criticism of social robotics as engaging humans in inauthentic social relations. However, fictionalist interpretations of the sociality in human-robot interactions are incoherent; social relations cannot be 'fictionalized'-I cannot treat an item as if it were a person since the performance of such a social action is constitutive for its realization [ ... ]. Rather, the de-realization in question should be understood as the as-if of simulation, where simulation is a similarity relation on processes; the latter can be used fairly straightforwardly for the definition of a fine-grained classificatory framework for simulated social interactions and associated degrees and types of sociality allowing for asymmetric (non-reciprocal) distributions of

23 Cf. "Posthuman Desire in Robotics and Science Fiction", by Sophie Wennerscheid (Wennerscheid 2018).

24 The idea of endowing the robots with emotions, feelings, and the ability to fall in love dates back to Karel Capek and his 1921 play Rossum's Universal Robots.

25 Regarding the voice of virtual assistant, which is a remarked question in the movie, project Q, designed by Virtue Nordics, created a genderless voice assistant. More information can be found at: https://www.youtube.com/watch? $\mathrm{v}=\mathrm{jasEIteA3Ag}$ and http://www.genderlessvoice.com/. 
capacities among interaction partners $[\ldots]$. This switch from the 'as-if' of fictionality to the 'as-if' of simulation - which fundamentally changes the premises for an ethical evaluation of human-robot interaction-is the cornerstone for a comprehensive descriptive framework for the interdisciplinary field of HRI [human-robot interaction studies].

(Seibt 2018, p. 392)

This switch from the 'as-if' of fictionality (ascribing feelings to robots) to the 'as-if' of simulation (behaviour patterns as though it has feelings) is a key point within this field. For example, the primary object of human-robot interaction studies is not how "a human playfully pretends to perform a social action towards a robot" but how "a robot simulates the performance of a social action towards a human". ${ }^{26}$ As argued by Levy (2007), when robots simulate human experiences, such as the one of lovers-namely with behaviour patterns that back them up, either by saying things such as "I love you" or like in the case of Her by showing jealously and willingness to please and to correspond -, the perception of them will influence the emotional attachment to them. It is this emotional attachment that allows robots' feelings to be accepted as true.

In any case, my point here is not to equate or approximate authenticity, either in human performance or in robot simulation, but to question the modes of production of both relevance and truth of authenticity (how can it be verified?); and to consider whether it is very different from the general human-human interaction. We might consider the modes of production (and programming) of truth, for instance, by summoning the symbolic function of ideology in the government of subjects within and through the ideological state apparatuses, as theorized by Louis Althusser (of religion, educational institutions or family, for example). As such, ideology and the ideological state apparatuses may be regarded as social programming devices or indoctrination devices that (aim to) inculcate ways of seeing and evaluating things; or as institutional algorithms that set human action and interaction as instructions and commands. In this sense, both humans and robots might be figured as running through operating systems, whence they attribute meaning and act accordingly.

Although from a distinct interpretive and analytical framework, David Levy establishes the same line of argument:

Some would argue that robot emotions couldn't be "real" because they have been designed and programmed into the robots. But is this very different from how emotions work in people? We have hormones, we have neurons, and we are "wired" in a way that creates our emotions. Robots will merely be wired differently, with electronics and software replacing hormones and neurons. But the results will be very similar, if not indistinguishable.

(Levy 2007, p. 122)

Indistinguishable, or not, the disputes around authenticity and uniqueness-either by equating ideological structural programming or neuronal-hormonal programming in the meaning production of the self and the world-tend to reveal more about the subject searching for it (assumptions, objectives and methods) than of the object sought.

Following the argument thread that social relations cannot be 'fictionalized', once the performance of such a social action is constitutive of its realization, let me introduce another example: Lars and the Real Girl, a 2007 comedy-drama film written by Nancy Oliver and directed by Craig Gillespie. Lars Lindstrom (played by Ryan Gosling), a sweet but socially awkward young man, living in a small village, ordered an anatomically correct sex doll, a "RealDoll", that he introduces to his family and community as his girlfriend, named Bianca, a wheelchair-mobile missionary of Brazilian and Danish

26 Regardless of, according to Seibt (Seibt 2018), the epistemic potential of the descriptions and discourses about properties of fictional characters and discourse about robotic capacities formulated with fictionality or the heuristic derealization operator "as-if". 
descent. In the movie, his family and community will adhere to what is understood as a delusion fantasy, and will treat Bianca as a real person. Thus, Bianca will be seen by the family doctor, will frequent the church, the hairdresser, and all public events. Eventually, Lars will announce that Bianca is sick and unresponsive, and after an ambulance rushes her to the hospital, she comes back home with a reserved prognosis. Bianca receives visits and flowers, and, soon after, while standing by a lake, Lars gives Bianca a very sad farewell kiss. Bianca is given a full-fledged funeral, well attended by the townspeople, and is buried in the local cemetery.

While the movie portrays the kindness and generosity of a community in a very uncommon manner, converging on the argument that relations cannot be fictionalized, and illustrating a possible scenario of parasocial relationships or post-human kinship, ${ }^{27}$ or a remake of a tale of statue-love, such as the story of Pygmalion, ${ }^{28}$ which can be found throughout classical antiquity (cf. Ferguson 2010; Smith 2013), my point is to hold on to Bianca to map some old and new disputes around transactional sex, merchandisable intimacy, and tamagotchization of care.

If Bianca was a real-size doll and Samantha a female artificial intelligence, a new generation of robotics is combining them both into an artificially intelligent "RealDoll" sex robot. As announced on the RealDollX website: "Goodbye loneliness! With RealDollX you can create and customize your own AI driven virtual RealDoll using cutting edge technology, and take her with you wherever you go". ${ }^{29}$ Constantly surpassing their level of realism, sex robots have increasingly resembled humans in height, weight, anatomy (including genitalia), body temperature, and skin-a synthetic skin with electronic sensors that allows them to react to touch and even to lubricate. Plus, the components of Artificial Intelligence have been enhanced, allowing these robots to establish and maintain conversations, to display a chosen personality profile, and to share common interests with the user; and even to develop seduction techniques, such as whispering. ${ }^{30}$ Commercialized by the US company Abyss Creations, these hyperrealist robots cost around $13,000 €{ }^{31}$

\section{Sex(y)-Robots}

The growing interest, research, and investment in sextech are both product and producer of several dilemmas that surround it: from cybersecurity, sextorsion, responsible robotics, robots that resemble children, animals, or celebrities, to asymmetrical affection and robotic consenting. Concerning cybersecurity and sextorsion, some research has been alerting to the possibility of robots becoming surveillance machines, through ransomware-a type of malicious software designed to block access to a computer system until a sum of money is paid (cf. Apa and Cerrudo 2018); ${ }^{32}$ illegal capture of videos and sounds, especially in intimate encounters that can be used by hackers to blackmail the users; or through the possibility of remotely operating a nice little robot to hurt humans (this one comprising

27 The vast psychological and anthropological literature on kinship has been articulating the configurations and boundaries between humans and machines, either within the discipline of 'cyborg anthropology', inspired in Donna Haraway construct of the cyborg-from its first conceptualization in 1992 (cf. Downey et al. 1995) to Amber Case success 'The Illustrated Dictionary of Cyborg Anthropology' (Case 2014); or from a mental health and therapeutic benefits perspective (loneliness, depression, anxiety) - e.g., Langcaster-James and Bentley (2018).

28 The story of Pygmalion is part of Ovid's epic poem Metamorphoses. In Ovid's narrative, Pygmalion was a Cypriot sculptor who fell in love with a sculpture he carved. He prays to goddess Aphrodite to bring the sculpture to life. Aphrodite grants his wish, and Pygmalion and Galathea lived happily ever after.

29 RealDollX website: https://www.realdollx.ai/.

30 Affective communication is being explored through "affective computing", which involves robots' ability to recognize emotional expressions, by measuring physiological indicators of emotion, such as heart rate or blood pressure (cf. Picard 2003).

31 "Hello Harmony: RealDoll sex robots with 'X-Mode' ship in September", available at: https://www.cnet.com/news/realdollsex-robots-with-x-mode-from-abyss-creations-ship-in-september/. After Harmony, Harmony 3.0 came to have a Tinder account, migrating in the meanwhile to Instagram. "The race to build the world's first sex robot", The Guardian, 27 April 2017, available at: https://www.theguardian.com/technology/2017/apr/27/race-to-build-world-first-sex-robot.

32 Cf. "Robots want Bitcoins Too!", by Lucas Apa and Cesar Cerrudo (Apa and Cerrudo 2018), available at: https: //ioactive.com/robots-want-bitcoins-too/. 
the discussion around responsible robotics ${ }^{33}$ ). My point here, though, is to focus on the ethical and/or legal dimensions entailed in the anthropomorphic attitude towards sex technologies, in and from which is anticipated or projected a possibility of humanity, of recreating humanity through convincing replicas; and, from the claim of robots as a technology of the orgasm or of robots as beings, to question its implications concerning the legal invocation, expression, and regulation (of sexuality) of the subjects.

But, first of all: what is this thing I have been calling sex-robots (or sex technology)? Not surprisingly, the intuitiveness and tautology that characterize the normative approaches to sexuality ${ }^{34}$ (conceived, regulated, and protected as a separate sphere of life) surface in sextech and sex-robots domains. As Francis X. Shen (Shen 2019) ${ }^{35}$ pointed out, there is no universally accepted definition of a sex-robot. This question is as important as the growing moral panic associated with it; and it is fundamental when it is in the sights of state regulation. According to Shen, the primary conundrum is how to distinguish between a sex-robot and a sexy robot: just because a robot is attractive to a human and can provide sexual gratification, does it deserve the label «sex-robot»?

It's tempting to define them as legislatures do sex toys, by focusing on their primary use. In Alabama, the only state that still has an outright ban on the sale of sex toys, the government targets devices "primarily for the stimulation of human genital organs." The problem with applying this definition to sex robots is that the latter increasingly provide much more than sex. Sex robots are not just dolls with a microchip. They will use self-learning algorithms to engage their partner's emotions. [ ... ] Humans, of course, can navigate both sexual and nonsexual contexts adeptly. What if a robot can do the same? How do we conceptualize and govern a robot that can switch from "play with kids" mode during the day to "play with adults" mode at night?

(Shen 2019)

How do we conceptualize and govern the erotic economy? Through its intention; its reception; its naming? Would it be different if, as Mitchell Langcaster-James and Gillian Bentley (Langcaster-James and Bentley 2018) suggested, they were named 'allodoll' (allo, a prefixed form of 'other', that according to the authors more accurately reflect the broader, non-sexual scope of the relationships)? Plus, do we have to? For what purposes? And how should or could erotic economy be governed? Under the epitome of obscenity? Of perversion? In addition, where and how are the boundaries between sexual and care to be defined? Are care-robots, for elderly or disabled persons, above suspicion? Elder-care-robots, in particular, are increasingly becoming objects of empathy (and have much contributed to the success, i.e., funding, of medical humanities), but what about childlike robots? Similarly to adultlike sex-robots or sex-dolls, where users report to brush the hair, dress, and to sit it (her? him? them?) at the dinner table and in the sofa in front of $\mathrm{TV},{ }^{36}$ childlike robots have occupied the place of tamagotchis: from baby-like robots for parental training, to surrogate siblings for children, ${ }^{37}$ to surrogate-partner therapy, including therapeutic use for treatment of paedophiles.

Concerning this last function, if fantasy criminalization and pathological subject rehabilitation-grounded on a subjectivation protocol based on the notions of guilt, remorse or

33 On this matter, Foundation for Responsible Robotics launch, in 2017, a report entitled "Our Sexual Future with Robots", which can be accessed at: https://responsiblerobotics.org/2017/07/05/frr-report-our-sexual-future-with-robots/.

34 What is sexual in sexual harassment is one of the questions I struggled with on my PhD thesis, in Feminists Studies (University of Coimbra), titled "The normative expression of harassment: socio-legal approaches to sexuality".

35 "Sex robots are here, but laws aren't keeping up with the ethical and privacy issues they raise", available at: https://theconversation.com/sex-robots-are-here-but-laws-arent-keeping-up-with-the-ethical-and-privacy-issues-theyraise-109852.

36 In the exploratory study conducted by Mitchell Langcaster-James and Gillian R Bentley (Langcaster-James and Bentley 2018) on the motivations and experiences of those who purchase and use sex dolls, the authors highlight the high prevalence of non-sexual, post-human companionship dynamics between dolls and their owners.

37 In January 2019, Sophia had a sibling: little Sophia, designed as an educational companion to help kids learn how to code. Available at: https://www.designboom.com/technology/sophia-the-robot-sister-little-sophia-01-31-2019/. 
regret, revised in the work of Tiago Ribeiro (e.g., Ribeiro 2018), are in line with the ideas proposed by therapeutic jurisprudence, the use of childlike sex-dolls has been discussed within the therapies developed for paedophiles. Its use, as a means to prevent first offences or recidivism, has led to severe disagreements: from the beliefs that expressing and accomplishing (sexual) desires with a childlike sex-robot would satiate users (to the point they would not need to hunt children); ${ }^{38}$ to the beliefs that it would encourage, reinforce, and normalize sexual encounters with children. ${ }^{39}$

Still, according to Shen (Shen 2019), although it is not clear whether anyone in the U.S. already owns a childlike sex robot, its possibility prompted a bipartisan House bill, the Curbing Realistic Exploitative Electronic Pedophilic Robots Act, or CREEPER. Introduced in 2017, it passed unanimously six months later. Perhaps someday, continues Shen, sex-robots will become sentient, but, for now, they are products: "Childlike sex robots are robots, not humans. Like virtual child pornography, the development of a childlike sex robot does not require interaction with any children". In Portugal, pornographic material with a realistic representation of underage individuals is a typified crime (since 2007), even though there is no children involved (thus, no victim). Analogously, one could also argue that childlike sex robots may have serious detrimental effects that compel state action. ${ }^{40}$

As a technology of the orgasm, sex-robots have been the target of abolitionist campaigns ${ }^{41}$ that resort to the traditional arguments of objectification and commodification of women's bodies, to arguments over social isolation and related intimacy problems, and to arguments regarding possible therapy (mis)uses and their potential nexus with sexual crimes. As a quasi-being, humanoid sex-robots, or sexbots, have been instigating disputes around morality and authenticity of emotions and ultimately the right to choose. It is to this last dimension that I will now turn to.

\section{Manufacturing Sentience}

Having robots take on the role of partner in relationships with human beings is, according to Levy (2007), a natural continuation of the trend in robotics research and development-a process that has already passed through various stages, from industrial robots, to service robots, to virtual pets, to companion and caregiver robots for the elderly. The current stage comprises "the design and construction of partner robots, sufficiently humanlike and sufficiently appealing in various ways to be considered as our true partners" (Levy 2007, p. 304). During the past few years, neurorobotics is testing the limits of a reimagined version of the story of Pygmalion, by attempting to manufacture consciousness, and thus subjectivity. Combining biological components with robotic design, Lovotics ${ }^{42}$ operates

38 "Paedophiles 'could be prescribed child sex dolls' to prevent real attacks, says therapist", Independent, 2 August 2017, available at: https://www.independent.co.uk/news/uk/home-news/paedophiles-child-sex-dolls-prescription-stop-attackschild-protection-stopso-therapists-a7872911.html; "Can Child Dolls Keep Paedophiles from Offending?”, The Atlantic, 11 January 2016, available at: https://www.theatlantic.com/health/archive/2016/01/can-child-dolls-keep-pedophiles-fromoffending/423324/; “Paedophiles buying lifelike child sex dolls to 'save children from sexual abuse'“, Express, 15 January 2016, available at: https://www.express.co.uk/news/world/634996/Paedophiles-buying-lifelike-child-sex-dolls-to-save-childrenfrom-sexual-abuse.

39 "Sick sex dolls that look like children - and the paedophiles who pay $£ 6000$ to import them into the UK", Mirror, 23 December 2017, available at: https://www.mirror.co.uk/news/uk-news/sick-sex-dolls-look-like-11745759.

40 A curious note: in many ban claims, on the pictures portraying childlike dolls or robots, the pictures of the body are pixelated. “'THIS ISN'T RIGHT' Sex robots looking like CHILDREN openly on sale in China as companies make them small enough to carry, expert warns", the Sun, 7 November 2018, available at: https:/www.thesun.co.uk/news/7679813/sex-robots-look-likechildren-china/.

41 For example, Kathleen Richardson's campaign against sex-robots, which has reached considerable international visibility, takes the exploitation and violence arguments against prostitution and argues that the development of sex-robots not only fosters the objectification of women and children, as it reinforces the co-existing sex trade demands. Richardson's campaign against sex-robots can be find at: https://campaignagainstsexrobots.org/. Recovering the barricades of Sex Wars, Kubes (2019) points out how the feminist critique (and the repeated calls for a complete ban) on sex robots "finds itself in the odd neighbourhood of anti-feminist conservatives arguing strongly in favour of restricted sexual morals" (Kubes 2019, p. 225). In her essay, Kubes presents what she understands as "a feminist alternative to the outright rejection of sex robot and robot sex" (Kubes 2019, p. 225), "thus contributing to a sex-positive utopian future" (Kubes 2019, p. 224).

42 Lovotics refers to the research on the human-to-robot relationship. David Levy, Adrian David Cheok, and Hooman Samani are some of the most prominent names in this field of study. 
through three modules: an artificial endocrine system (based on physiology of love), a probabilistic love assembly (based on psychology of love) and an affective state transition (based on emotions). ${ }^{43}$

Trying to recreate human sexual attraction and mate selection, neurorobotics reduces the subjects and the social world to its epistemic lens and framework and entitles, outlines, standardizes, and mimics the animality of humans as a way to humanize robotics, by inscribing a virtual pheromone system in robotics—and here lays the great epistemic schizophrenia: the self-determination sovereignty (identity as a device of power and knowledge) is being accompanied by a renewed emphasis on biological evidence that reduces to (sex) hormones (and other neurochemicals) the understanding and the fabrication of the truth of subjects, subjectivities, and interactions. ${ }^{44}$ Moreover, the faith in scientific progress has inspired much of the debate over the legal, ethical, and design implications of sexbots.

Concerning design implications, hormones and its impact and influence as a subject's subjectivity generator are currently the king of the party. Mackenzie (2018), among other authors, starts from the apprehended human cognitive-affective neural architecture ${ }^{45}$ to advocate that "balance [between oxytocin and vasopressin and between oxytocin and testosterone] in robotic equivalents is a crucial, albeit challenging enterprise when designing intimate sexual companions for humans to promote harmonious relationships, ethical conduct, and psychological stability" (Mackenzie 2018, p. 78). It is precisely these possibilities and alleged equivalence of designing/falsifying chemistry/subjectivity that raises (and may eventually answer to) the legal and ethical problems. It is such equivalences that inspire legal and ethical implications such as the following: from the moment that techno-scientific work (biomimetic and biohybrid engineering) has mastered the creation of sentient, self-aware robots, including sexbots, whatever that means, robots will no longer be understood as things and, as such, the question will be centered on whether sexual intimacy is possible, lawful, and ethical between unequal sentient beings. As Mackenzie (2018, P. 73) puts it: "humans as creators should have a duty to protect the interests of created sentient beings and to minimize their suffering, which should be enshrined in ethical, legal, and design regulation before becoming pre-empted by technological advances". This duty derives from the projection that humans-a certain anthropological conception of humans-will want to feel that the love they have for sexbots is reciprocal and unique; and that sexbots "will possess the autonomy to choose whether to love us or not, self-awareness and subjectivity" (Mackenzie 2018, p. 74).

Rousi (2018), drawing on a hypothetical future scenario in which robots actually possess their own emotions, and the ability to love, adds a dilemma (a simultaneous fear and fascination known as the Frankenstein Syndrome): what if, in that speculative plan, robots "have the right to express their own free will and exercise their powers of life and love partner selection" (Rousi 2018, p. 45) and prefer other robots over humans? "[ ... ] how to maintain the interest of the robot?" (Rousi 2018, p. 48). From the responsibility of creating free will, to the risks of creating free will, will humans be afraid that robots will laugh at them; while robots will be afraid that humans will shut them down? (a Margaret Atwood quote wordplay).

From free will to consenting is a short distance, and regarding consenting we can leave the speculative plane, when Science is able to create sentience, thus emotions (love, sorrow, lust, etc.). In the end of 2017, during an Ars Electronica event in Austria, Samantha, a sex-robot created by Sergi Santos, was molested and seriously damaged by some attendees. This incident made Sergi

43 Lovotics platform: http://www.lovotics.com/.

44 On this matter, take the notions of the body as a laboratory, introduced by Preciado (2008) in Testo Junkie. Combining auto-political fiction, auto-theory, and body-essay, Testo Junkie describes a protocol of voluntary intoxication based on synthetic testosterone. This bodily experimentation, which allows Preciado the fiction of being a sexual-hacker or a sex-pirate, is presented as a means of renewing the sense of the self. "Preciado's porno-political fictions of the body" will be shortly published in Revista Estudos Feministas (Oliveira).

45 This cognitive-affective neural architecture is based, namely, (i) on the premise that "[t]he balance between oxytocin and vasopressin may prove particularly productive in designing sexbots, as in some, though not all, mammalian species, it determines monogamy or non-monogamy in pair bonds" (Mackenzie 2018, p. 78); and (ii) on the premise of an appropriate balance of oxytocin and testosterone to prevent maladaptive human social functioning. 
Santos take the decision of allowing sex-robots to decline sex, namely if the user is aggressive. ${ }^{46}$ This opened a new discussion on ethics and reciprocity. If, as announced by Levy (2007), it is a matter of time-according to Levy, fifty years-for weddings (or a formal contract) between humans and robots to be allowed (in some countries, at least), how can this reciprocity to be acknowledged and assured? Well, if we take this question seriously, then why not to expand this concern to other areas of robotics technology? How can we be sure that the vacuum cleaner accepts to vacuum the dust? Or the stereo system to listen to reggaeton? To what extent the anthropomorphisation of robotics is the criterion to acknowledge its possibility of humanity? Of self-awareness or sentience? Or sex is the criterion for ethical duties? What about the ethical duty to pay a salary to elder-care-robots or other about-to-come sentient entities? When did it stop being about humans and robots' capacity to satisfy all their needs? About "great sex on tap for everyone, 24/7", as announced by Levy (2007) at the very end of his Love and Sex with Robots?

From digital citizenship, to digisexuality, to new wars on terror, tamagotchization of intimacy or care one can see where the barricades will form over what is anticipated, rendered, and protected as sexual. One last example on this concerns the use of robots for health and biomedical progresses. Let me introduce you to Victoria: a human-patient simulator who gives birth to a baby-robot, complete with a heartbeat. ${ }^{47}$ With silicone skin and flexible members, Victoria bleeds, has blood pressure, contractions, and responds to 200 commonly used drugs. Victoria is used to practise doctor-patient communication, childbirth maneuvers, and postpartum haemorrhages. What about consent? Can consenting to pregnancy be a question here, or should we think of Victoria as only a derivative of a CPR training manikin? On the other hand, does the correct anatomical genitalia make it (her?) a sex-robot or not? Maybe a potential sex-robot? Again, what makes a robot a sex-robot? Is it the materiality of the body-robot or the meaning attributed to it? And, in case of the latter, is it the meaning that is constitutively attributed to it as a her or as a him ${ }^{48}$ Considered from the perspective of a technology of the orgasm, does the question become instead not about the doll or the robot itself, but of what it indicates and reveals about the subject? And, in this case, is it a sex-doll or a sex-robot an indicator of the subject hazardousness? Whereas, from the perspective of a technology of manufacturing a projection of the human (humanoid), will it transform-or, in this game of mirrors, will it be endowed or allowed to transform - the anthropological conception of the human itself?

Maybe, after all, these are not even or-or propositions, and, by challenging the dominant ideas of what it implies to be human, it densifies the anthropocentric ideals of liberal humanism. A humanism that has assumed the sovereignty that was once delegated to a transcendent entity, god or gods, and which, by continuously producing itself and/through otherness, is claiming the credits for engendering, governing, and saving its self-proclaimed posthuman world.

\section{Final Remarks}

If it is from the potential of metaphors that new ecophilosophical dimensions claim new forms of existence-creatures between worlds, cyborg, postsex, posthuman, and humanoid-and new forms of hyphenation, then it is important to understand whether metaphors produce transformation in experience, describe transformations in experience, or merely stage a transformation that, in these terms, does not even exist-or exists, but is irrelevant for this or other purposes.

The sequence of prefixes_-post, neo, trans, inter, and eco-reveals, results, or competes (and probably all of the above) for the search for common references, denominators, and identities.

46 How he would do that, it has not become clear; whether through awareness of its material integrity, or the incorporation of a typified and combinatorial repertoire of words and behaviors.

47 "Pregnant Robot Gives Birth: Tech Meets Medicine", available at: https://www.youtube.com/watch?v=25hqWUXcDdA.

48 I understand the epistemic, epistemological and semiotic operation of assigning sexual sense and meaning to robots as constitutive of the sex-regime, and as such the bionic representation of the feminine is anything but random or gratuitous. However, this is an issue to be explored in a future text. 
Within a context of theory-fatigue (as theorized by Braidotti 2013), the productive synthesis of self and others (Braidotti 2013, p. $2^{49}$ ) becomes a meme-a meme of «I»-identity-commodity; «I»-means-of-production-of-the-self; «I»-meaning-producing-sign. The memefication of identity and the metaphoricity of theories to think the existence can be seen in formulations such as human rights of animals or human rights of machines; or of claims like Emile Ratelband's right to be young again; or Raphael Samuel's right not to be born; or Sophia's right to resign and emancipate itself (herself?) from the Hanson Robotics company or even the deliberate shutdown of Sophia to be considered murder; or 'androidism', coined by Anthony Ferguson (2010), as a robot-sexual orientation, ${ }^{50}$ or the legal claims to marry with a robot as anticipated and advertised in David Levy work.

Contemporary debates over the meanings of the subject and its legal modes of (auto-) signification and mediation (statal, organizational, interactional, identitarian) repeatedly lead to a certain sense of trouble; troubles that enlighten its problematic status and that result from the mismatch between its radical concreteness, positionality, and singularity and the legal method to devise and regulate abstractions. The cases presented in this essay put the subject in jeopardy both through its concreteness (to feel therefore to claim the right to be (young); or to exist therefore to claim the right not to have existed) and through its abstraction (the equivalence between nationality and (civil) existence; or to feel therefore to claim the right to be (human)).

Curiously, the features that subjects seem to have at their legal disposal converge with the features that are, at least for now, testing the boundaries of the legal recognition of robots as legal subjects (e.g., nationality, sex identification, marriage status). In this sense, not only anthropomorphism figures as the answer to the question of what defines which robots are to be made subjects, as it implies to have (and to be) what is understood as a pre-discursive truth of the human, a sex. Within the field, at least, the idea has become dominant that it is through sex-sentience that techno-scientific research anthropomorphizes silicone and microfibers and devises it as a real (and sentient) (human) being. It is therefore through this sex-sentience in the anthropomorphization of things and concepts that human exceptionalism is challenged (after all, what counts as human?)—and a person hazardousness is admeasured (eminently when it resembles or foresees any resemblance with children). At the same time, though, this reinforces anthropocentrism, by expounding the political act of the making of human and non-human things.

This tech-given life (a god-given drift) finds resonance in the expression and method of the law-given life (as the making of legal persons and legal non-persons). As theorized by David Delaney (Delaney 2016), in an anthology on lively legalities, law animates the inanimate:

[... ] every "thing" is always potentially a legal thing in so far as it is positionable within the signifying grids of property and sovereignty. The body is a legal thing, the uterus is a legal thing, the city is a legal thing, the ocean is a legal thing. Through the incorporation of things into the dynamic networks of social relations of power law could be understood as animating the inanimate.

(Delaney 2016, p. 216)

If, as Delaney continues, world is now a legal thing; life as such has become a legal thing, and potentially all inanimate are legally animatable; the subject, if it ever existed, is little more than a humanist hologram. As such, the postulate of posthuman as a figuration (as ascribed by Braidotti 1991), or a conceptual

49 For a diagonal understanding on this matter, cf. Rosi Braidotti (Braidotti 2018), "Posthuman Critical Theory".

50 The online community called iDollators is creating its own grammar: iDollator culture, technosexuals, robossexuals, robosexuality, Synthetik humans, and so forth. Davecat, one of the most visible iDollator, introduces himself as "a Synthetiks advocate": "What that means is that I try to promote the idea of artificial humans, whether they're life-sized Dolls or humanoid robots such as Gynoids and Androids, in a positive manner. I also often focus on how Synthetik humans can be valid and valuable partners for those of us Organiks who are open-minded enough to the possibilities of embracing technology, both figuratively and literally". An interview with Davecat can be found here: https://futureofsex.net/robots/ idollator-culture-inside-minds-men-love-dolls/. 
persona (according to Deleuze and Guattari 1994), translates a postconceptual condition into a legal postsubject. Thus, the dispute may be not in terms of acknowledging and expanding legal personality to things, either robot, pet, river, or humanoid, but to hollow out the subject to the point of a relational legal thing. It may epitomize a kind of melancholia of unpayable ontological debts; a science fiction reverie of the abolition of the subject-surpassing xenofeminism, which syndicates an anti-naturalistic stance with techno-materialism and binary gender abolitionism; and multiple ecologies of knowledge and knowing subjects, such as cyborg, quasi-objects, hybridism, or the production of hybrid actors, theorized by Haraway (1991), Latour (1993), or Gray (2002). As Donna Haraway (Haraway 2016, p. 35) wrote: "[i]t matters what thought think thoughts, what knowledges know knowledges, what relations relate relations, what worlds world worlds, it matters what stories story stories". Paraphrasing Haraway, we could say: 'it matters what subjects subject subjects'; or, better still, it is a matter of (what are the) subjects subjecting subjects with which law is being challenged. Nevertheless, the impasse I end this essay with is this: what things thing things; and in this sense, it is a matter of legal things legal thinging legal things. This is, however, anything but a novelty: it is still a matter of cartography of power and knowledge.

Funding: This research received no external funding.

Conflicts of Interest: The author declares no conflict of interest.

\section{References}

Althusser, Louis. 1970. Idéologie et appareils idéologiques d'État. (Notes pour une recherche). La Pensée 151: 3-38. Apa, Lucas, and Cesar Cerrudo. 2018. Robots want Bitcoins Too! IOActive. Available online: https://ioactive.com/ robots-want-bitcoins-too/ (accessed on 30 October 2019).

Baars, Grietje. 2019. Queer Cases Unmake Gendered Law, Or, Fucking Law's Gendering Function. Australian Feminist Law Journal 45: 15-62. [CrossRef]

Braidotti, Rosi. 1991. Patterns of Dissonance: On Women in Contemporary French Philosophy. Cambridge: Polity.

Braidotti, Rosi. 2013. The Posthuman. Cambridge: Polity.

Braidotti, Rosi. 2018. Posthuman Critical Theory. In Posthuman Glossary. Edited by Rosi Bradotti and Maria Hlavajova. London: Bloomsburt Academic, pp. 339-42.

Braidotti, Rosi. 2019. Posthuman Knowledge. Cambridge: Polity Press.

Butler, Judith. 1990. Gender Trouble. Feminism and the Subversion of Identity. New York: Routledge.

Case, Amber. 2014. The Illustrated Dictionary of Cyborg Anthropology. Scotts Valley: CreateSpace Independent Publishing Platform.

Delaney, David. 2016. Lively ever after: Beyond the Cult of Immateriality. In Animals, Biopolitics, Law. Lively Legalities. Edited by Irus Braverman. New York: Routledge.

Deleuze, Gilles, and Felix Guattari. 1994. What is Philosophy? New York: Columbia University Press.

Downey, Gary Lee, Joseph Dumit, and Sarah Williams. 1995. Cyborg Anthropology. Cultural Anthropology 10: 264-69. [CrossRef]

Ferguson, Anthony. 2010. The Sex Doll. A History. London: McFarland \& Company, Inc.

Fineman, Martha Albertson, and Nancy Sweet Thomadsen, eds. 1991. At the Boundaries of Law. Feminism and Legal Theory. New York: Routledge.

Foucault, Michel. 1982. The Subject and Power. Critical Inquiry 8: 777-95. [CrossRef]

Gray, Chris. 2002. Cyborg Citizen: Politics in the Posthuman Age. New York: Routledge.

Hall, Stuart. 1996. Introduction. Who needs "Identity". In Questions of Cultural Identity. Edited by Stuart Hall and Paul du Gay. London: Sage, pp. 1-17.

Haraway, Donna. 1991. Simians, Cyborgs and Women: The Reinvention of Nature. New York: Routledge.

Haraway, Donna. 2016. Staying with the Trouble. Making Kin in the Chthulucene. Durham: Duke University Press.

Harris, Angela P. 1990. Race and Essentialism in Feminist Legal Theory. Stanford Law Review 42: 581-616. [CrossRef]

Kubes, Tanja. 2019. New Materialist Perspectives on Sex Robots. A Feminist Dystopia/Utopia? Social Sciences 8 : 224. [CrossRef] 
Lacey, Nicola. 1998. Unspeakable Subjects: Feminist Essays in Legal and Social Theory. Oxford: Hart Publishing.

Langcaster-James, Mitchell, and Gillian R. Bentley. 2018. Beyond the Sex Doll: Post-Human Companionship and the Rise of the 'Allodoll? Robotics 7: 62. [CrossRef]

Latour, Bruno. 1993. We Have Never Been Modern. Translated by Catherine Porter. Cambridge: Harvard University Press.

Levy, David. 2007. Love and Sex with Robots, The Evolution of Human-Robot Relationships. London: Harper Perennial.

Mackenzie, Robin. 2018. Sexbots: Customizing Them to Suit Us versus an Ethical Duty to Created Sentient Beings to Minimize Suffering. Robotics 7: 70. [CrossRef]

Merry, Sally Engle. 1994. Law, Jurisprudence, and Social Thought: Colonialism, Post-Colonialism, and Legal Theory. Political and Legal Anthropology Review 17: 95-100. [CrossRef]

Naffine, Ngaire. 2003. Who are Law's Persons? From Cheshire Cats to Responsible Subjects. The Modern Law Review Limited 66: 346-67. [CrossRef]

Oliveira, Ana. Forthcoming. Preciado's porno-political fictions of the body. Revista Estudos Feministas.

Picard, Rosalind. 2003. Affective computing: Challenges. International Journal of Human-Computer Studies 59: 55-64. [CrossRef]

Preciado, Beatriz. 2008. Testo yonki. Madrid: Espasa Calpe.

Ramalho, Maria Irene. 2001. A sogra de Rute ou intersexualidades. In Globalização: Fatalidade ou Utopia? Edited by Boaventura de Sousa Santos. Porto: Edições Afrontamento, pp. 525-55.

Ribeiro, Tiago. 2018. Sex, blah blah blah and all that mess: Notas sobre a regulação jurídica e política do sexo. Imprópria 6: 21-35.

Roberts, Carys, Henry Parkes, Rachel Statham, and Lesley Rankin. 2019. The Future is Ours. Women, Automation and Equality in the Digital Age. Available online: https://www.ippr.org/files/2019--07/the-future-is-ourswomen-automation-equality-july19.pdf (accessed on 27 September 2019).

Rousi, Rebekah. 2018. Me, My Bot and His Other (Robot) Woman? Keeping Your Robot Satisfied in the Age of Artificial Emotion. Robotics 4: 44. [CrossRef]

Seibt, Johanna. 2018. Robophilosophy. In Posthuman Glossary. Edited by Rosi Bradotti and Maria Hlavajova. London: Bloomsburt Academic, pp. 390-93.

Shen, Francis X. 2019. Sex robots are here, but laws aren't keeping up with the ethical and privacy issues they raise. The Conversation. Available online: https://theconversation.com/sex-robots-are-here-but-laws-arentkeeping-up-with-the-ethical-and-privacy-issues-they-raise-109852 (accessed on 2 September 2019).

Smart, Carol. 1989. Feminism and the Power of Law. London: Routledge.

Smith, Marquard. 2013. The Erotic Doll: A Modern Fetish. New Haven: Yale University Press.

Spinoza, Benedict. 1994. A Spinoza Reader: The Ethics and Other Works. Translated and Edited by Edwin Curley. Princeton: Princeton University Press.

Trovato, Gabriele, Cesar Lucho, and Renato Paredes. 2018. She's Electric-The Influence of Body Proportions on Perceived Gender of Robots across Cultures. Robotics 7: 50. [CrossRef]

Wennerscheid, Sophie. 2018. Posthuman Desire in Robotics and Science Fiction. In Love and Sex with Robots. Edited by Adrian David Cheok and David Levy. London: Springer, pp. 37-50.

(C) 2020 by the author. Licensee MDPI, Basel, Switzerland. This article is an open access article distributed under the terms and conditions of the Creative Commons Attribution (CC BY) license (http://creativecommons.org/licenses/by/4.0/). 